Working Paper 2009:19

Department of Economics

Non-uniform staggered prices and output persistence

Johan Söderberg 
Department of Economics

Working paper 2009:19

Uppsala University

December 2009

P.O. Box 513

ISSN $1653-6975$

SE-751 20 Uppsala

Sweden

Fax: +46184711478

Non-UNIFORM STAGGERED PRICES AND OUTPUT PERSISTENCE

JOHAN SÖDERBERG

Papers in the Working Paper Series are published on internet in PDF formats.

Download from http://www.nek.uu.se or from S-WoPEC http://swopec.hhs.se/uunewp/ 


\title{
Non-uniform staggered prices and output persistence
}

\author{
Johan Söderberg*
}

December 17, 2009

\begin{abstract}
Staggered prices are a fundamental building block of New Keynesian dynamic stochastic general equilibrium models. In the standard model, prices are uniformly staggered, but recent empirical evidence suggests that deviations from uniform staggering are common. This paper analyzes how synchronization of price changes affects the response to monetary policy shocks. I find that even large deviations from uniform staggering have small effects on the response in output. Aggregate dynamics in a model of uniform staggering may serve well as an approximation to a more complicated model with some degree of synchronization in price setting.
\end{abstract}

Keywords: Price setting, Staggering, Synchronization, Persistence

JEL codes: E31, E32

*Department of Economics, Uppsala University, Box 513, SE-751 20 Uppsala, Sweden, e-mail: johan.soderberg@nek.uu.se 


\section{Introduction}

There is little disagreement in the literature that monetary policy shocks have persistent effects on output, nor that this is a consequence of prices and wages not being continuously reoptimized. There is also little disagreement that the effect on output lasts longer than the typical price or wage contract. The literature tries to explain this through staggered pricing models, in the spirit of Taylor (1980) and Calvo (1983), where only a fraction of price setters reoptimize in every period. The key insight is that price setters, who are able to change their price after a monetary policy shock, realize that many prices remain fixed and therefore change their price less than they would if all prices were changed at the same time.

The central role of staggered prices in New Keynesian DSGE models has spurred an interest in investigating this issue empirically. The FK index, proposed by Fisher and Konieczny (2000), is a measure of the degree of synchronization in price setting. This index takes a value of zero under uniform (perfect) staggering and a value of one under perfect synchronization. A principal finding is that the degree of synchronization in price setting varies depending of the level of aggregation. A high degree of staggering is found when the FK index is applied to data that has been aggregated to a few broad product categories. For example, Dhyne et al. (2005) found that the median FK index for the euro area is 0.18 when calculated across 50 product categories. In contrast, considerable synchronization is typically found at low levels of aggregation. Using Belgian producer price data, Cornille and Dossche (2006) found that, for about 80 percent of the product categories at the NACE 4-digit level, the FK index lies between 0.25 and $0.75 .^{1}$ Thus, there is a considerable degree of synchronization within individual markets.

The purpose of this paper is to investigate how partial synchronization affects macroeconomic dynamics. The main question is whether staggered price models still have the ability to generate sufficient output persistence, once the assumption of

\footnotetext{
${ }^{1}$ See also Cornille and Dossche (2008). Dhyne and Konieczny (2007) found a similar result for consumer prices. They also emphasized the importance of geographical aggregation, with synchronization being the highest at the city level. This view is confirmed by Veronese et al. (2005), using Italian consumer price data.
} 
uniform staggering is relaxed. In the first part of this paper, I answer this question by solving a simple, analytically tractable Taylor pricing model, where prices are fixed for two (overlapping) periods. I study how deviations from uniform staggering affect the economy by varying the fraction of firms setting their prices in odd and even periods. The main finding is that the cumulative effect on output of a monetary policy shock is a non-linear function of the degree synchronization. Small deviations from uniform staggering have small effects on output persistence, but small deviations from perfect synchronization have large effects.

In the second part of the paper, I extend the analysis to a general equilibrium model. To account for the fact that the degree of synchronization varies with the level of aggregation, I use a model with two levels in the demands system. There are many sectors, each sector corresponding to an individual product category. In each sector, there is a large number of firms, each having some monopoly power because it produces a different brand. Prices are uniformly staggered at the aggregate level, but there is some degree of synchronization within sectors.

Since prices are uniformly staggered at the aggregate level, the model is always able to produce some persistence in output, regardless of the degree of synchronization at the sector level. However, the literature has recognized the need of real rigidities to create sufficient persistence to match the response in output found in data. Eichenbaum and Fisher (2007) emphasize that a model where the elasticity of demand varies along a firm's demand curves, as in Kimball (1995), and firm-specific capital, where a firm's marginal cost is an increasing function of the firm's demand, is consistent with data. These real rigidities interact with staggering by slowing down price adjustment as demand is reallocated from price adjusters to non-adjusters. Hence, in the below, I consider a model with these sources of real rigidities.

For a plausible calibration of real rigidities, I find that there is much more persistence when prices at the sector level are uniformly staggered, compared to when they are perfectly synchronized. However, as in the simple two-period model, the mapping between the degree of synchronization and the persistence of the effect on output is highly non-linear. Deviations from uniform staggering have small effects on output. Therefore, aggregate dynamics in a model with uniform staggering may 
serve well as an approximation to the dynamics of a more complicated model with some degree of synchronization in price setting.

The remainder of this paper is organized as follows: in the section below, I solve a simple two-period Taylor model analytically. The full model is presented in Section 3 , and Section 4 shows the results from the numerical simulations. Section 5 presents the conclusions.

\section{A Taylor model with an analytical solution}

Assume an economic environment with a continuum of monopolistically competitive firms, indexed by $i \in[0,1]$. The firms are divided into two cohorts. In each cohort, prices are set every other period and fixed for two periods. The cohort consisting of price setters setting their prices in even periods encompasses a fraction $\alpha \in[0,1]$ of the firms, and the cohort consisting of price setters setting their prices in odd periods a fraction $1-\alpha$. In the absence of any price setting frictions, the optimal "frictionless" time $t$ price $\widetilde{p}_{i t}$ is determined by

$$
\widetilde{p}_{i t}-p_{t}=\phi y_{t}, \quad \phi>0
$$

where $p_{t}$ is the price level and $y_{t}$ is aggregate real activity. ${ }^{2}$ Lower case variables denote $\log$-deviations from steady state values. A firm allowed to reoptimize sets its reset price $p_{i t}^{*}$ as an average of the expected frictionless prices over the two periods the price remains fixed:

$$
\left(p_{i t}^{*}-p_{t}\right)+\left(p_{i t}^{*}-E_{t} p_{t+1}\right)=\phi\left(y_{t}+E_{t} y_{t+1}\right)
$$

The price level is obtained by integrating over all individual prices:

$$
p_{t}=\int_{0}^{1} p_{i t} d i .
$$

\footnotetext{
${ }^{2}$ This equation can be derived from microfoundations, see Romer (2001).
} 
The model nests the Taylor (1980) model of uniformly staggered pricing as a special case when $\alpha=1 / 2$. If instead $\alpha=0(=1)$, all prices are set in odd (even) periods and price setting is perfectly synchronized. For intermediate values of $\alpha$, prices are neither uniformly staggered nor perfectly synchronized. One can use the FK index, defined as

$$
\sqrt{\frac{1}{T} \frac{\sum_{t=1}^{T}\left(\alpha_{t}-\bar{\alpha}\right)^{2}}{\bar{\alpha}(1-\bar{\alpha})}},
$$

where $T$ is the sample size, $\alpha_{t}$ the proportion of the firms changing their price between periods $t-1$ and $t$, and $\bar{\alpha}$ the sample mean of $\alpha_{t}$, to map the value of $\alpha$ into a measure of the degree of synchronization in price setting. In the present model the FK index is

$$
\begin{aligned}
F K & =\sqrt{2\left(\alpha-\frac{1}{2}\right)^{2}+2\left((1-\alpha)-\frac{1}{2}\right)^{2}} \\
& =\sqrt{2\left(\alpha^{2}+(1-\alpha)^{2}-\frac{1}{2}\right)} \\
& =\sqrt{1-4 \alpha(1-\alpha)} .
\end{aligned}
$$

To close the model, I assume that aggregate demand is determined by the quantity theory relation

$$
y_{t}=m_{t}-p_{t},
$$

and that money supply $m_{t}$ is a random walk

$$
m_{t}=m_{t-1}+\varepsilon_{t}
$$

where $\varepsilon_{t}$ is a white noise process with finite variance. Substituting (5) into (1), the frictionless optimal price can be rewritten as

$$
\widetilde{p}_{i t}=\phi m_{t}+(1-\phi) p_{t} .
$$


The degree of strategic complementarity in price setting is determined by the partial derivative of the optimal price, with respect to the price level. If $\phi<1$ prices are strategic complements and if $\phi>1$, they are strategic substitutes. It is well-known in the literature that strategic complementarity provides the basis for models with nominal rigidities to explain persistent effects on output, following monetary policy shocks. As we shall see later, the degree of strategic complementarity also plays an important role for how deviations from uniform staggering affect output dynamics.

Under these assumptions, the model can be solved analytically. It turns out that output evolves according to the first order difference equation:

$$
y_{t}=\gamma_{I} y_{t-1}+\omega_{I} \varepsilon_{t},
$$

where $I$ is a variable taking a value of one in odd periods and a value of two in even periods, and $\gamma_{I}$ and $\omega_{I}$ are given by

$$
\begin{aligned}
\gamma_{1} & =\frac{(1-\alpha) \lambda_{1}+\alpha}{\alpha \lambda_{2}+(1-\alpha)} \lambda_{2}, \\
\omega_{1} & =(1-\alpha) \lambda_{1}+\alpha,
\end{aligned}
$$

and

$$
\begin{aligned}
\gamma_{2} & =\frac{\alpha \lambda_{2}+(1-\alpha)}{(1-\alpha) \lambda_{1}+\alpha} \lambda_{1}, \\
\omega_{2} & =\alpha \lambda_{2}+(1-\alpha),
\end{aligned}
$$

where $\lambda_{1}$ and $\lambda_{2}$ are obtained by solving the system

$$
\begin{aligned}
& \lambda_{1}-A_{1}\left(\lambda_{1} \lambda_{2}+1\right)=0 \\
& \lambda_{2}-A_{2}\left(\lambda_{1} \lambda_{2}+1\right)=0
\end{aligned}
$$


and

$$
\begin{aligned}
A_{1} & =\frac{\alpha(1-\phi)}{2(\phi+\alpha(1-\phi))}, \\
A_{2} & =\frac{(1-\alpha)(1-\phi)}{2(\phi+(1-\alpha)(1-\phi))} .
\end{aligned}
$$

The details of this derivation are in Appendix A. When $\alpha \neq \frac{1}{2}$, the response in output to a shock to the money supply will be different depending on whether the shock hits in an even or an odd period. To analyze the model, I start with two special cases. The first result pertains to the case with perfect synchronization.

Proposition 1 If $\alpha=0$, then the solution to the system in (9) - (12) is given by $\gamma_{1}=0, \gamma_{2}=0, \omega_{1}=0$, and $\omega_{2}=1$. If $\alpha=1$, then the solution is given by $\gamma_{1}=0$, $\gamma_{2}=0, \omega_{1}=1$ and $\omega_{2}=0$.

If $\alpha=0(=1)$, a shock to money supply is neutral in odd (even) periods. If instead the shock occurs in an even (odd) period, all prices are fixed in advance and the shock to money supply fully transmitted into output. The effect on output is not persistent, however, and output returns to steady state in the following period, when all price setters are allowed to change their prices.

The inability of monetary policy to create persistent effects in output should be understood in the light of how prices are set in this economy. Combining (2) with (5) and (6), the optimal reset price can be written as

$$
p_{i t}^{*}=\phi m_{t}+\frac{(1-\phi)}{2}\left(p_{t}+E_{t} p_{t+1}\right)
$$

Imposing $p_{t+1}=p_{t}=p_{i t}^{*}$, this reduces to $p_{i t}^{*}=m_{t}$. This is exactly the same price that price setters would have chosen if there were no price setting frictions. Thus, the increase in money supply is completely absorbed into prices, whenever price setters are given the opportunity to (simultaneously) reoptimize.

The second result pertains to the case when prices are neither strategic complements nor strategic substitutes. 
Proposition 2 If $\phi=1$, then, $\forall \alpha \in[0,1]$, the solution to the system in (9) - (12) is given by $\gamma_{1}=0, \gamma_{2}=0, \omega_{1}=\alpha$ and $\omega_{2}=1-\alpha$.

If $\phi=1$, the effect on output following an increase in money supply in the period that the shock occurs is proportional to the fraction of non-adjusters in that period. Output however is not persistent and returns to steady state in the following period, when the first round of price adjustments is completed. Again, the lack of persistence is a result of price setters, whenever they are allowed to reoptimize, choosing the same price that they would have in a frictionless economy. The increase in money supply is completely absorbed into prices, once all price setters have been given the opportunity to reoptimize after the shock.

The third result pertains to the general case when prices are not perfectly synchronized and are either strategic substitutes or complements.

Proposition 3 If $\alpha \in(0,1)$ and $\phi \neq 1$, then the stable solution $\left(\gamma_{1}\right.$ and $\gamma_{2}$ inside the unit circle) to the system in (13) and (14) is given by

$$
\lambda_{1}=\frac{1-\sqrt{1-4 A_{1} A_{2}}}{2 A_{2}}
$$

and

$$
\lambda_{2}=\frac{1-\sqrt{1-4 A_{1} A_{2}}}{2 A_{1}} .
$$

In terms of output dynamics, this implies that $\omega_{1}$ and $\omega_{2}$ are always positive, while $\gamma_{1}$ and $\gamma_{2}$ are positive (negative) if $\phi<1(>1)$.

Irrespective of whether prices are strategic complements or substitutes, an increase in the money supply has, by (8), a positive effect on output. When prices are strategic complements, the adjustment in output back to steady state is sluggish. In contrast, when prices are strategic substitutes, the adjustment in output back to steady state is, because $\gamma_{1}$ and $\gamma_{2}$ are negative, oscillating. This behavior of output when prices are strategic substitutes has previously been noted by, e.g., Romer (2001) in the case of uniformly staggered prices, but generalizes to the more general case when prices are partially synchronized. Such an adjustment path is 
clearly counterfactual, and I therefore focus on the case when prices are strategic complements. $^{3}$

In order to compare impulse responses for different values of $\alpha$, one needs a measure of the persistence of the effect. For this purpose, it is convenient to work with the expected cumulative effect on output. As discussed in Carvalho (2006), this measure takes into account both the duration and real effect of the response in output following a shock. In Appendix B I show that expected cumulative effect on output, $E_{t} \sum_{k=o}^{\infty} y_{t+k}$, following an unexpected shock of size $\varepsilon$ to money supply at time $t$, can be written as

$$
\frac{\left[\omega_{1}\left(1+\gamma_{2}\right)+\omega_{2}\left(1+\gamma_{1}\right)\right]}{1-\gamma_{1} \gamma_{2}} \frac{\varepsilon}{2} .
$$

When the model is unable to produce persistence in output, this measure takes on a particularly simple form.

Proposition 4 If $\alpha=0, \alpha=1$ or $\phi=1$ the expected cumulative effect on output is given by $\frac{\varepsilon}{2}$.

If prices are perfectly synchronized, a shock to money supply is, as described in Proposition 1, fully transmitted into output if the shock hits the economy in a period when prices are not adjusted. This causes an immediate increase in output of size $\varepsilon$; however output returns to steady state in the following period. If, instead, the shock hits the economy in a period when all prices are reoptimized, there is no effect on output. Since $\varepsilon_{t}$ is a random walk and equally probable to hit the economy in all periods, averaging over the response in output in odd and even periods yields the proposition above for $\alpha=0$ or $\alpha=1$. A similar argument can be applied to the case when $\phi=1$.

\footnotetext{
${ }^{3}$ In the simple model presented in Romer (2001), $\phi$ is the inverse of the labor supply elasticity, so that an, arguably, empirically plausible labor supply elasticity below unity implies $\phi>1$. Such a model, however, is too simplistic because it omits important sources of real rigidities. Such rigidities are included in the full model in Section 3.
} 
Proposition 5 If $\alpha \in(0,1)$ and $\phi \neq 1$, the expected cumulative effect on output is given by

$$
C(\alpha, \phi)=\left[\frac{1}{1-\phi} \Omega(\alpha, \phi)-1\right] \frac{\varepsilon}{2},
$$

where

$$
\Omega(\alpha, \phi)=\frac{1+\sqrt{1-4 A_{1} A_{2}}}{\sqrt{1-4 A_{1} A_{2}}}\left[2-(1+\phi) \sqrt{1-4 A_{1} A_{2}}\right],
$$

and $A_{1}$ and $A_{2}$ are given by (15) and (16).

The details of this derivation are in Appendix C. The properties of $\Omega(\alpha, \phi)$ are described in the following result:

Proposition 6 If $\alpha \in(0,1)$ and $\phi \neq 1: \Omega(\alpha, \phi)$ is a strictly concave function of $\alpha$ and $\arg \max _{\alpha} \Omega(\alpha, \phi)=\frac{1}{2}$.

The proof is in Appendix D. The expected cumulative effect on output is largest when there is uniform staggering. The next result follows as a corollary to Proposition 4 and Proposition 6.

Proposition 7 For all permissible values of $\alpha$ and $\phi$ :

$$
C_{11}(\alpha, \phi) \begin{cases}<0 & \text { if } \phi<1 \\ =0 & \text { if } \phi=1 \\ >0 & \text { if } \phi>1\end{cases}
$$

implying that $C$ is a strictly concave (convex) function of $\alpha$, if prices are strategic complements (substitutes). If prices are neither strategic complements nor strategic substitutes, $C$ is linear with respect to $\alpha$.

If $\phi \neq 1, C(a, \phi)$ is the flattest around uniform staggering $\left(\alpha=\frac{1}{2}\right)$ and the steepest when prices are perfectly synchronized. Thus, moving a small distance from uniform staggering has a much smaller effect on the expected cumulative effect on output than moving the same distance from perfect synchronization. Figure 1 plots the mapping between $\alpha$ and $C(a, \phi)$ for different values of $\phi$; the expected cumulative 


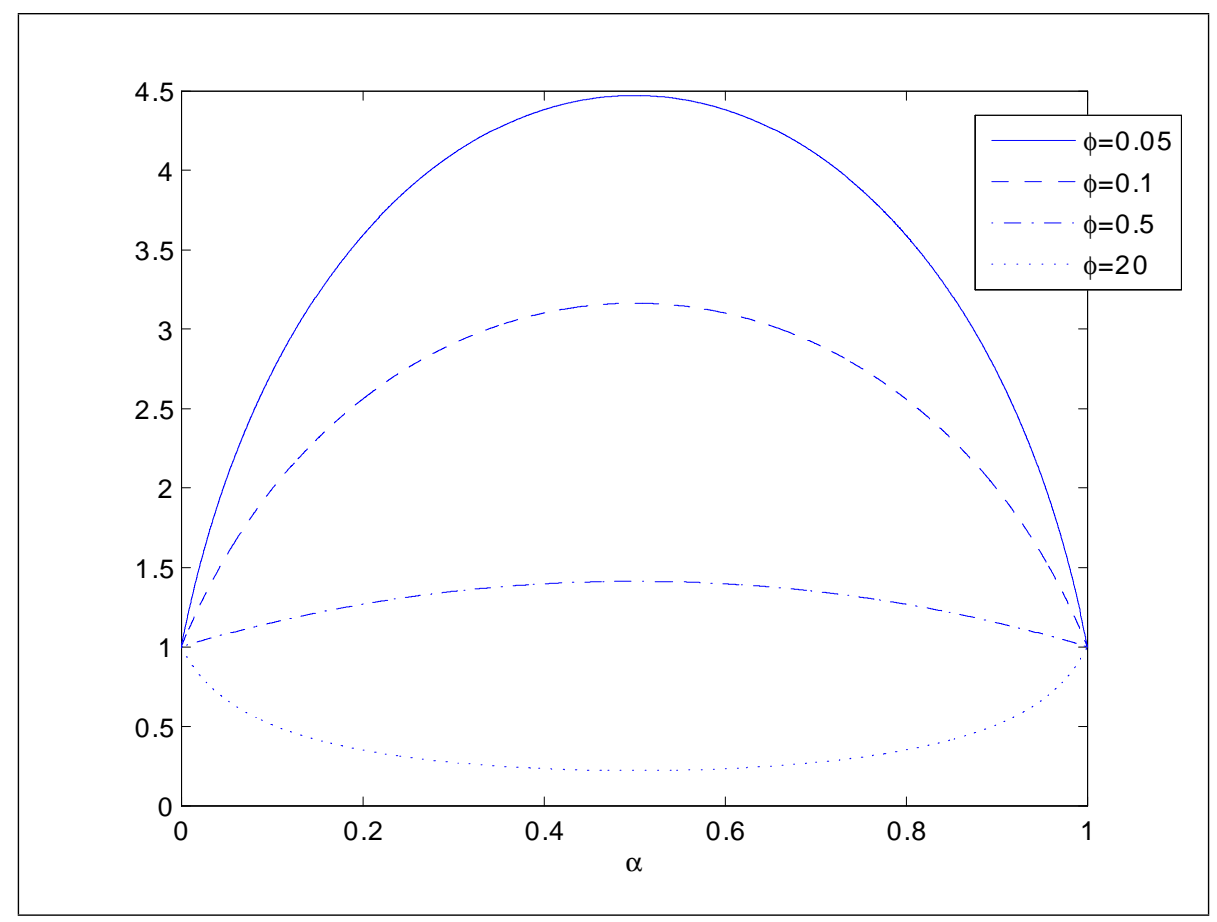

Figure 1: The mapping between $\alpha$ and the (normalized) expected cumulative effect on output for different values of $\phi$.

effect on output has been normalized so that the effect under perfect synchronization corresponds to one.

It turns out that, for a wide range of values of $\alpha$, output persistence is similar to the case of uniform staggering. Chari et al. (2000) argue that in order to match the U.S. business cycle, when prices are uniformly staggered, one needs $\phi=0.05$. Then, even for values of $\alpha$ as low as 0.2 , the model is able to generate a substantial persistence. One can further assess this claim by mapping the associated values of $\alpha$ into the corresponding FK index. Figure 2 plots the relation between this index and the expected cumulative effect on output, expressed as a fraction of the response under uniform staggering. For instance, when the FK index is 0.25 , the expected cumulative effect on output is 97 percent of the response with uniform staggering. Increasing the amount of synchronization so that the FK index is 0.5 , the expected 


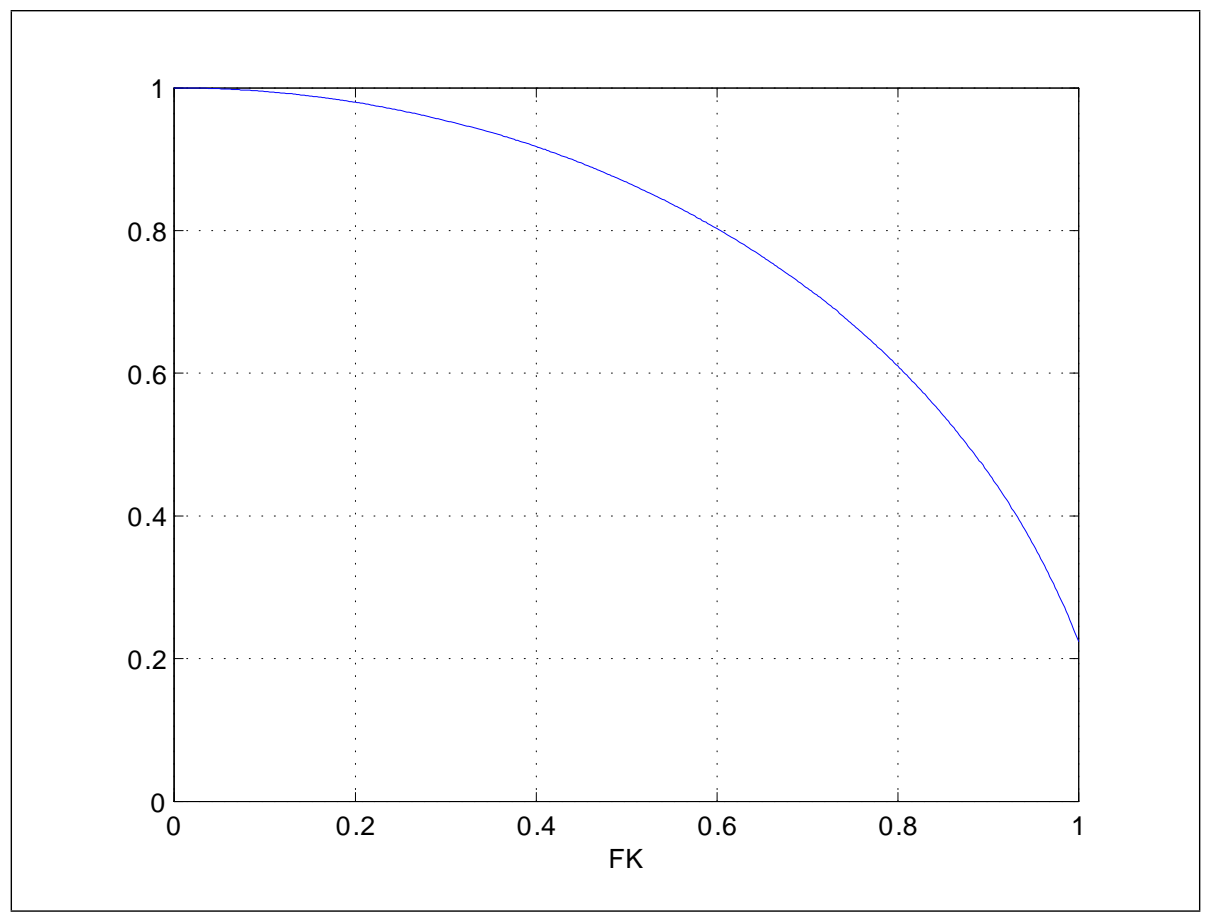

Figure 2: The expected cumulative effect on output, as a fraction of the response under uniform staggering, for different values of the FK index when $\phi=0.05$. The FK index takes a value of zero under uniform staggering and a value of one under perfect synchronization.

cumulative effect on output is still close to uniform staggering, as 87 percent of the response remains. Even when the FK index is as high as 0.75, 67 percent of the response under uniform staggering remains. If prices are perfectly synchronized, on the other hand, the expected cumulative effect on output is only 22 percent of what it is under uniform staggering.

To understand the reason for this highly non-linear relation between $\alpha$ and $C(\alpha, \phi)$, consider how prices are set. The price level is

$$
p_{t}=(1-\alpha) p_{t}^{*}+\alpha p_{t-1}^{*}
$$


in odd periods and

$$
p_{t}=\alpha p_{t}^{*}+(1-\alpha) p_{t-1}^{*}
$$

in even periods. ${ }^{4}$ Assuming that $t$ is odd, one can write the optimal reset price in (17) as

$$
p_{t}^{*}=\left(1-2 A_{1}\right) m_{t}+A_{1}\left(p_{t-1}^{*}+E_{t} p_{t+1}^{*}\right) .
$$

Suppose that $\alpha$ is low, so that a large fraction of all firms are reoptimizing, and that price setters take $E_{t} p_{t+1}^{*}$ as given. Then, because $A_{1}$ is a monotonically increasing function of $\alpha$ (see (15)), the optimal price will be heavily influenced by the money supply and little by past and future prices, and vice versa. But price setters rationally realize that next period's optimal price will be set according to the condition

$$
p_{t+1}^{*}=\left(1-2 A_{2}\right) m_{t+1}+A_{2}\left(p_{t}^{*}+E_{t+1} p_{t+2}^{*}\right) .
$$

Here, a low $\alpha$ implies that a small fraction of all firms are reoptimizing and that the optimal price will be heavily influenced by past and future prices and little by the money supply. Substituting this equation into (22), imposing $E_{t} m_{t+1}=m_{t}$ and rearranging, we get

$$
p_{t}^{*}=\frac{1}{1-A_{1} A_{2}}\left[\left(1-A_{1}-2 A_{1} A_{2}\right) m_{t}+A_{1} p_{t-1}^{*}+A_{1} A_{2} E_{t} p_{t+2}^{*}\right]
$$

where $A_{1} A_{2}=\frac{1}{4} \frac{\alpha(1-\alpha)(1-\phi)^{2}}{\phi+\alpha(1-\alpha)(1-\phi)^{2}}$. A higher $A_{1} A_{2}$ implies that price setters are more forward-looking, in the sense that they place a larger weight on $E_{t} p_{t+2}^{*}$ and a smaller weight on $m_{t}$. For a given $\phi, A_{1} A_{2}$ depends primarily on $\alpha(1-\alpha)$. As a consequence, the influence by future optimal prices on this period's optimal price is the largest when $\alpha=\frac{1}{2}$. The concavity of $A_{1} A_{2}$ with respect to $\alpha$ implies that, as we move away from $\alpha=\frac{1}{2}$, today's optimal price is still heavily influenced by future optimal prices and less by the money supply. Therefore, small deviations from uniform staggering have small effects on the price-setting behavior.

\footnotetext{
${ }^{4}$ Since all firms in a cohort set the same optimal price, the subscript identifying individual firms has been dropped.
} 


\section{The full model}

The simple model in the previous section provides a convenient and analytically tractable framework but is too simplistic to be realistic. I therefore extend the analysis to incorporate the basic building blocks that characterize the canonical New Keynesian framework. On the demand side, households maximize utility and the central bank implements an interest rate rule. On the supply side, there are monopolistically competitive, profit-maximizing firms, with staggered price setting. I make two modifications to the baseline New Keynesian framework. First, the elasticity of demand varies along the demand curve and capital is firm-specific. Second, the economy consists of many sectors and prices are uniformly staggered between sectors, but there is some synchronization within sectors. The first modification, underlined by Eichenbaum and Fisher (2007), introduces real rigidities which help to reconcile the New Keynesian model with micro evidence on the frequency of price adjustment. The second modification is consistent with empirical studies of the degree of synchronization in price setting; see e.g. Cornille and Dossche (2006).

\subsection{Households}

The economy consists of a large number of sectors. The representative household derives utility from the consumption of composite goods, according to the following generalized (Kimball) aggregator:

$$
1=\int_{0}^{1} F\left(C_{i t} / C_{t}\right) d i,
$$

where $C_{i t}$ denotes consumption of the composite good in sector $i \in[0,1]$ and $C_{t}$ is aggregate consumption. Each composite good consists of a large number of brands, produced in each sector, from which the household derives utility according to the 
aggregator:

$$
1=\int_{0}^{1} G\left(C_{i j t} / C_{i t}\right) d j,
$$

where $C_{i j t}$ denotes consumption of brand $j \in[0,1]$ in sector $i$. The household allocates consumption expenditure between the different brands in different sectors to

$$
\min _{C_{i j t}} \int_{0}^{1} \int_{0}^{1} P_{i j t} C_{i j t} d j d i,
$$

where $P_{i j t}$ denotes the price of brand $j$ in sector $i$, subject to (25) and (26) for a given $C_{t}$. The decision can be seen as sequential: in the first step, the household allocates consumption across sectors and then, in the second step, allocates across brands within each sector. Solving this problem backwards yields that demand for brand $j$ in sector $i$ is given by

$$
C_{i j t}=G^{\prime-1}\left(\frac{P_{i j t}}{P_{i t}} D_{i t}\right) C_{i t},
$$

where

$$
P_{i t}=\frac{1}{C_{i t}} \int_{0}^{1} P_{i j t} C_{i j t} d j
$$

is the price level in sector $i$, and

$$
D_{i t}=\int_{0}^{1} G^{\prime}\left(\frac{C_{i j t}}{C_{i t}}\right) \frac{C_{i j t}}{C_{i t}} d j .
$$

Taking (27) as given, it follows that demand for the sector $i$ composite good is given by

$$
C_{i t}=F^{\prime-1}\left(\frac{P_{i t}}{P_{t}} D_{t}\right) C_{t}
$$


where

$$
P_{t}=\frac{1}{C_{t}} \int_{0}^{1} P_{i t} C_{i t} d i
$$

is the aggregate price level, and

$$
D_{t}=\int_{0}^{1} F^{\prime}\left(\frac{C_{i t}}{C_{t}}\right) \frac{C_{i t}}{C_{t}} d i
$$

Demand for a specific brand thus depends on the brand's relative price in the sector, but also on the sector's relative price level and aggregate demand.

The representative household solves the intertemporal problem:

$$
\max _{\left\{C_{t+k}, N_{t+k}, B_{t+k}\right\}_{k=0}^{\infty}} E_{t} \sum_{k=0}^{\infty} \beta^{k}\left\{\frac{1}{1-\sigma_{C}} C_{t+k}^{1-\sigma_{C}}-\frac{1}{1+\sigma_{N}} N_{t+k}^{1+\sigma_{N}}\right\},
$$

where $\beta \in(0,1)$ is the household's subjective discount factor and $N_{t}=\int_{0}^{1} \int_{0}^{1} N_{i j t} d j d i$ is the number of working hours supplied, subject to the budget constraint

$$
B_{t}+P_{t} C_{t}=R_{t-1} B_{t-1}+W_{t} N_{t}+\Phi_{t}
$$

where $B_{t}$ denotes bond holdings, $R_{t}$ is the gross nominal interest rate, $W_{t}$ is the nominal wage, and $\Phi_{t}$ is dividends from firm ownership. The associated first order conditions for consumption and bond holdings reduce to the Euler equation

$$
C_{t}^{-\sigma_{C}}=\beta E_{t} \frac{R_{t}}{\Pi_{t+1}} C_{t+1}^{-\sigma_{C}}
$$

where $\Pi_{t}=\frac{P_{t}}{P_{t-1}}$ is the gross inflation rate. In addition, the first order condition for labor supply is

$$
\frac{N_{t}^{\sigma_{N}}}{C_{t}^{-\sigma_{C}}}=\frac{W_{t}}{P_{t}}
$$




\subsection{Firms}

Brand $j$ in sector $i$ is produced by a monopolist with technology

$$
Y_{i j t}=N_{i j t}^{\gamma}
$$

where $N_{i j t}$ denotes the firm's input of labor, rented on the perfectly competitive, economy-wide labor market, and capital is assumed to be fixed at the firm level. ${ }^{5}$ All firms are owned by the households, and profits are paid out in the form of dividends at the end of each period.

Each sector is divided into $N$ cohorts of size $\alpha_{1} \alpha_{2} \ldots \alpha_{N}$, where $\alpha_{i} \in[0,1] \forall i$ and $\sum_{i=1}^{N} \alpha_{i}=1$. The cohorts are arranged within each sector according to their sectorial indices, so that firms indexed $j \in\left[0, \alpha_{i}\right]$ constitute the first cohort in sector $i$, firms indexed $j \in\left[\alpha_{i}, \alpha_{i}+\alpha_{i+1}\right]$ constitute the second cohort, and so on; Figure 3 illustrates this graphically for the case when $N=4$. Prices are fixed for $N$ periods

\begin{tabular}{|c|c|c|c|c|}
\hline & \multicolumn{4}{|c|}{ Cohort } \\
\hline & 1 & 2 & 3 & 4 \\
\hline \multirow{4}{*}{ 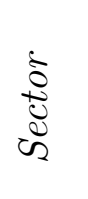 } & $\alpha_{1}$ & $\alpha_{2}$ & $\alpha_{3}$ & $\alpha_{4}$ \\
\hline & $\alpha_{2}$ & $\alpha_{3}$ & $\alpha_{4}$ & $\alpha_{1}$ \\
\hline & $\alpha_{3}$ & $\alpha_{4}$ & $\alpha_{1}$ & $\alpha_{2}$ \\
\hline & $\alpha_{4}$ & $\alpha_{1}$ & $\alpha_{2}$ & $\alpha_{3}$ \\
\hline
\end{tabular}

Figure 3: The size of the cohorts within each sector when $N=4$.

and set in a staggered fashion. In particular, the firms in the first cohort in each sector set their prices at time $t=0, N, 2 N, \ldots$, the second cohort at $t=1, N+1,2 N+1, \ldots$, and so on. This assumed price setting behavior has two important implications. First, prices are uniformly staggered at the aggregate level because a constant fraction of all prices are reset in each period. Second, when not all cohorts are of equal

\footnotetext{
${ }^{5}$ This corresponds to the limiting case when adjustment costs approach infinity in the model of Eichenbaum and Fisher (2007). As discussed in Woodford (2005), this simplifying assumption is of little consequence for price setting dynamics.
} 
size, there is some degree of synchronization at the level of the individual sector. This specification captures, in a stylized way, the idea that there is much more coordination within sectors than in the aggregate.

Given these restrictions, a firm's objective is to maximize the profit stream:

$$
E_{t}^{i j} \sum_{k=0}^{N-1} \beta^{k} \Delta_{t, t+k}\left[P_{i j t} Y_{i j t+k}-W_{t+k} N_{i j t+k}\right]
$$

where $E_{t}^{i j}$ denotes the firm's time $t$ expectations operator and $\beta^{k} \Delta_{t, t+k}=\beta^{k}\left(\frac{C_{t+k}}{C_{t}}\right)^{-\sigma_{C}}\left(\frac{P_{t}}{P_{t+k}}\right)$ is the firm's nominal stochastic discount factor, subject to the demand and technological constraints in (27) and (31). This implies the price setting rule

$$
E_{t}^{i j} \sum_{k=0}^{N-1} \beta^{k} \Delta_{t, t+k} Y_{i j t+k}\left[\left(1-\eta\left(X_{i j t+k}\right)\right) P_{i j t}-\eta\left(X_{i j t+k}\right) S_{i j t+k}\right]=0
$$

where $S_{i j t}=\frac{1}{\gamma} W_{t} N_{i j t}^{1-\gamma}$ is the marginal cost and $\eta\left(X_{i j t}\right)=\frac{-G^{\prime}\left(X_{i j t}\right)}{X_{i j t} G^{\prime \prime}\left(X_{i j t}\right)}$ is the elasticity of demand, at market share $X_{i j t}=\frac{Y_{i j t}}{Y_{i t}}$, between brands in the sector. As discussed in Kimball (1995), the generalized aggregator function allows the generation of any desired shape of the individual firm's demand curve, by using different specifications of $G\left(X_{i j t}\right)$. As customary in the literature, I restrict my attention to the case when $\eta^{\prime}\left(X_{i j t}\right)<0$, so that a firm's elasticity of demand is a decreasing function of its market share. Such a specification is consistent with, e.g., the imperfect information model in Ball and Romer (1990), where a price increase drives away more old customers than a price decrease attracts new ones. The fear of losing customers makes firms reluctant to change their prices and slows down price adjustment.

\subsection{Price setting}

To understand how the varying elasticity of demand and firm-specific capital affect price setting, it is instructive to log-linearize the price setting condition above, which, 
after some manipulations, reads

$$
E_{t} \sum_{k=0}^{N-1} \beta^{k}\left(p_{i j t}-p_{t+k}\right)=A D E_{t} \sum_{k=0}^{N-1} \beta^{k} s_{t+k}+\left(1-\frac{A D}{B}\right) E_{t} \sum_{k=0}^{N-1} \beta^{k}\left(p_{i t+k}-p_{t+k}\right)
$$

where $s_{t}$ is aggregate real marginal cost. In addition to expected movements in aggregate marginal cost, the firm should also respond to expected movements in the gap between the sector's and the aggregate price level. This gap depends on the degree of synchronization in price setting.

Consider first the case when prices are uniformly staggered at the sector level. Price setting within sectors is staggered and demand is being reallocated between firms in the same sector. However, because the proportion of reoptimizers is the same in all sectors, all firms, regardless of which sector they belong to, set the same price, whenever they are able to reoptimize. As a consequence, $p_{i t}=p_{t}$ and there is no reallocation of demand between sectors. In this case, (33) reduces to

$$
E_{t} \sum_{k=0}^{N-1} \beta^{k}\left(p_{i j t}-p_{t+k}\right)=A D E_{t} \sum_{k=0}^{N-1} \beta^{k} s_{t+k}
$$

which is similar to the price setting condition in Eichenbaum and Fisher (2007). The parameter $A=\frac{1}{1+\varsigma \epsilon} \leq 1$ captures the effect of the varying demand elasticity. The parameter $\epsilon$ is the steady state elasticity of a firm's demand elasticity with respect to its relative price, $\varsigma=\frac{\eta}{\eta-1}-1$ is the steady state markup, and $\eta$ is the steady state elasticity of substitution between brands. Consider a firm contemplating raising its price, following an increase in marginal cost. The firm realizes that the price increase also lowers its market share in the sector and thus makes its demand curve more elastic. This reduces the "pass-through" from marginal cost into prices, and the higher $\epsilon$ is, the stronger this effect, as the demand elasticity rises more when the price increases.

The parameter $D=\frac{1}{1+\eta \omega_{p} A}$ captures the effect of firm-specific capital, where $\omega_{p}=\frac{1-\gamma}{\gamma}$ is the elasticity of a firm's marginal cost with respect to its demand. A firm increasing its price, following an increase in marginal cost, also reduces its 
demand and thereby its marginal cost, which reduces the desire to further increase the price. The higher $\omega_{p}$ is, the stronger is this effect, as the firm's marginal cost falls more when demand falls.

If we instead assume that prices are perfectly synchronized, all firms in a sector change their prices at the same time and there is no reallocation of demand between firms in the same sector. However, because price setting is coordinated within sectors, and prices are staggered at the aggregate level, demand will be reallocated between sectors. Since $p_{i j t}=p_{i t}$ in this case, the price setting condition in (33) reduces to ${ }^{6}$

$$
E_{t} \sum_{k=0}^{N-1} \beta^{k}\left(p_{i j t}-p_{t+k}\right)=B E_{t} \sum_{k=0}^{N-1} \beta^{k} s_{t+k} .
$$

The parameter $B=\frac{1}{1+\theta \omega_{p}}$ captures the effect of firm-specific capital, where $\theta$ is the steady state elasticity of substitution between different product categories (sectors). Analogous to the argument above, firm-specific capital reduces the desired price increase. But here the reduction in marginal cost occurs because demand is reallocated between sectors. Because the firm's market share, $X_{i j t}$, is constant, there is no real rigidity from the Kimball aggregator.

As I shall argue below, for a reasonable calibration, $A D$ is much smaller than $B$; in other words, there are more real rigidities within than between sectors. Comparing (34) and (36) we see that the effect on prices, following an increase in marginal cost, is smaller, and output is more persistent, when prices are uniformly staggered, than when they are perfectly synchronized. Supposedly, which will be confirmed in the next section, there is a negative relationship between the degree of synchronization and the persistence in output. To determine the quantitative properties of this

$$
\begin{aligned}
& { }^{6} \text { Subtracting } E_{t} \sum_{k=0}^{N-1} \beta^{k} p_{i t+k} \text { from both sides of (33) and rearranging yields } \\
& \qquad E_{t} \sum_{k=0}^{N-1} \beta^{k}\left(p_{i j t}-p_{i t+k}\right)=A D E_{t} \sum_{k=0}^{N-1} \beta^{k} s_{t+k}-\frac{A D}{B} E_{t} \sum_{k=0}^{N-1} \beta^{k}\left(p_{i t+k}-p_{t+k}\right) .
\end{aligned}
$$

Imposing $p_{i j t}=p_{i t+k} \forall k \geq 0$, rearranging and dividing by $\frac{A D}{B}$ gives (36) in the text. 
Table 1: Calibration.

\begin{tabular}{lll}
\hline \hline Parameter & Value & Description \\
\hline$\beta$ & $0.95^{1 / 4}$ & Household's subjective discount factor \\
$\sigma_{N}$ & 1 & Inverse of (Frisch) labor supply elasticity \\
$\sigma_{C}$ & 1 & Inverse of intertemporal elasticity of substitution \\
$\eta$ & 11 & Elasticity of substitution between brands \\
$\theta$ & $1 / 2$ & Elasticity of substitution between product categories \\
$\epsilon$ & 33 & Kimball parameter \\
$\gamma$ & $2 / 3$ & Labor elasticity of output \\
$\phi_{\pi}$ & 1.5 & Inflation coefficient in the interest rate rule \\
$\phi_{y}$ & 0.125 & Output gap coefficient in the interest rate rule \\
$\rho_{r}$ & 0.3 & Degree of interest rate smoothing \\
$\rho_{\nu}$ & 0.87 & Serial correlation of monetary policy shocks \\
\hline
\end{tabular}

relationship, the model needs to be calibrated and solved numerically.

\section{Aggregate dynamics}

The model is closed by assuming that monetary policy is implemented by an interest rate rule, which in log-linearized form reads:

$$
r_{t}=\left(1-\rho_{r}\right)\left(\phi_{\pi} \pi_{t}+\phi_{y} y_{t}\right)+\rho_{r} r_{t-1}+\nu_{t}
$$

where

$$
\nu_{t}=\rho_{\nu} \nu_{t-1}+\varepsilon_{t}^{r}
$$

and $\varepsilon_{t}^{r}$ is a white noise process with finite variance.

Table 1 summarizes the calibration, where one period is assumed to be one quarter. This implies a steady state annual interest rate of about 5 percent and log utility in consumption and leisure. Following Carrillo et al. (2007), the degree of interest rate smoothing is assumed to be relatively low, while shocks to the interest rate rule are highly persistent. I also adopt their specification of the coefficients in the interest rate rule. 
I set $\eta$ to 11 and $\theta$ to $1 / 2$ in order to match the high price elasticity between brands and the low price elasticity between product categories, as estimated by, e.g., Hausman et al. (1994) and, more recently, Levin and Yun (2008); this implies a 10 percent steady state markup. The value of $\epsilon$ implies that, without nominal rigidities, the "pass-through" from marginal cost into prices is 23 percent. The value of $\gamma$ corresponds to a labor share of $2 / 3$ and $\omega_{p}=0.5$. These values imply $\frac{A D}{B}=0.1276$, confirming the conjecture that a reasonable calibration assigns more real rigidities within than between sectors. This is because between sectors there is $i$ ) no real rigidity from the Kimball aggregator, as the elasticity of demand is solely a function of a firm's market share in the sector and ii) little real rigidity from firm-specific capital, as the demand elasticity between product categories is very small.

Prices are assumed to be fixed for one year, i.e., $N=4$. What remains is to set $\alpha_{1}, \alpha_{2}, \alpha_{3}$ and $\alpha_{4}$. Unlike the simple two-period model, the mapping from the (sector level) FK index to the size of the cohorts is, in general, not unique. One approach is to generate a set $S$, whose members are the size of the cohorts, from a function with geometrically declining weights:

$$
S=\left\{\frac{(1-x)}{\left(1-x^{4}\right)} x^{n-1}: \quad n=1, \ldots, 4\right\} .
$$

Substituting this into the definition of the FK index, yields that the mapping between the FK index and $x$ is given by

$$
x^{4}+c x^{3}+c x^{2}+c x+1=0
$$

where $c=\frac{2}{3} \frac{\left(3 F K^{2}+1\right)}{\left(F K^{2}-1\right)}$. This quasi-symmetric quartic equation has two real roots and both have the same implications for $S{ }^{7}$ There are $4 !=24$ permutations of $S$, but 18 of these are rotations of the additional 6 sequences, amounting to a mere rearranging of the sectorial indices without affecting the model's aggregate dynamics.

\footnotetext{
${ }^{7}$ Using the change of variable $z=x+x^{-1}$, (38) can be written as the quadratic equation $z^{2}+c z+(c-2)=0$. It follows that $x=\frac{z \pm \sqrt{z^{2}-4}}{2}$, where $z=\frac{-c \pm \sqrt{c^{2}-4(c-2)}}{2}$. For each root of $z$, the first root of $x$ is the multiplicative inverse of the second root.
} 


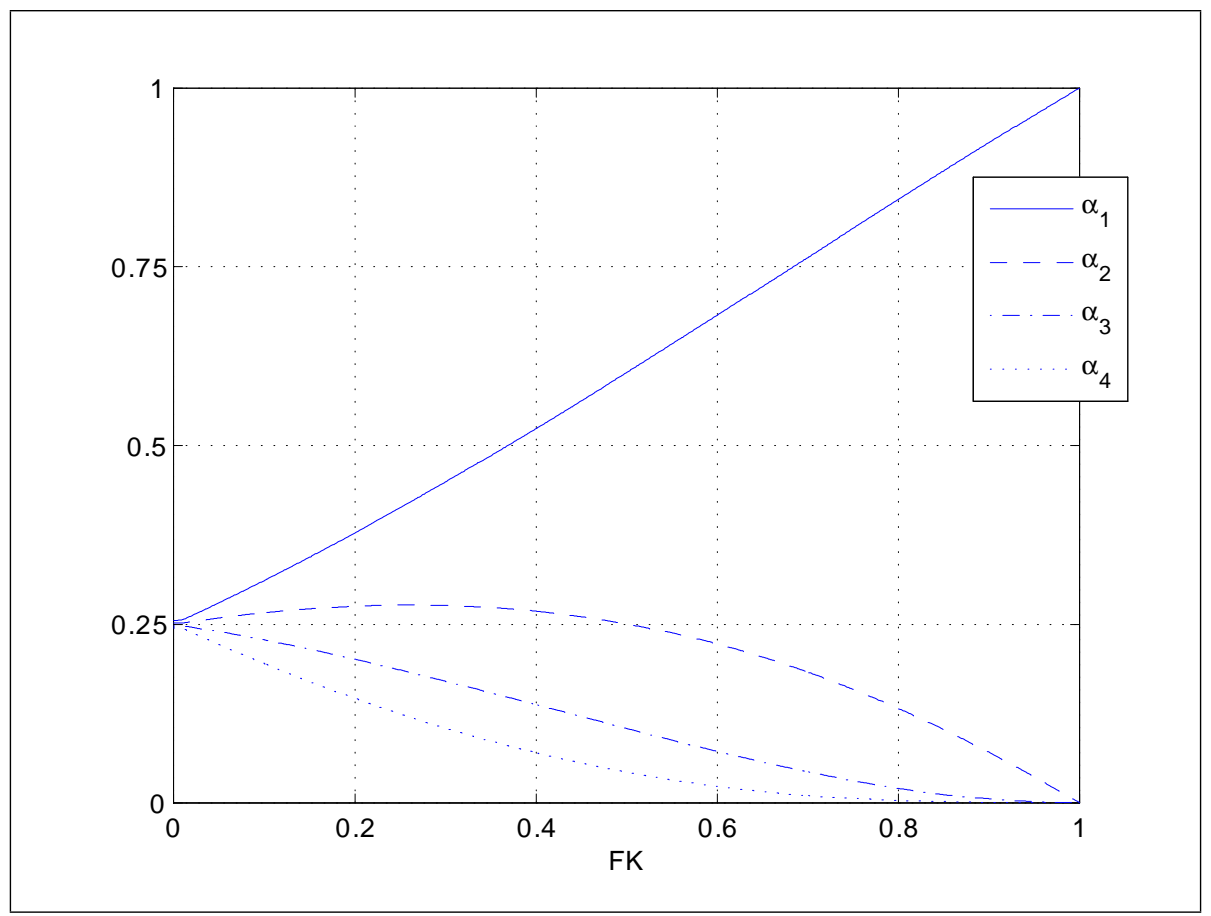

Figure 4: The mapping between the FK index and the size of the cohorts. The FK index takes a value of zero under uniform staggering and a value of one under perfect synchronization.

Quantitatively, I find that the choice of sequence has a small impact on the expected cumulative effect on output; I therefore restrict attention in the text to the monotonically declining sequence where $\alpha_{1} \geq \alpha_{2} \geq \alpha_{3} \geq \alpha_{4}{ }^{8}$ Figure 4 plots the mapping between the FK index and the size of the cohorts under this assumption.

To explore how deviations from uniform staggering affect aggregate output in this model, I again calculate the expected cumulative effect on output, for various values on the FK index. ${ }^{9}$ Figure 5 plots this relationship as a fraction of the response under uniform staggering. As discussed in the previous section, an economy with uniformly staggered prices produces a much more persistent response in output than

\footnotetext{
${ }^{8}$ This consequence of choosing alternative sequences is analyzed in Appendix E.

${ }^{9}$ For this simulation, the Dynare software, available at http://www.cepremap.cnrs.fr/dynare/, has been used.
} 


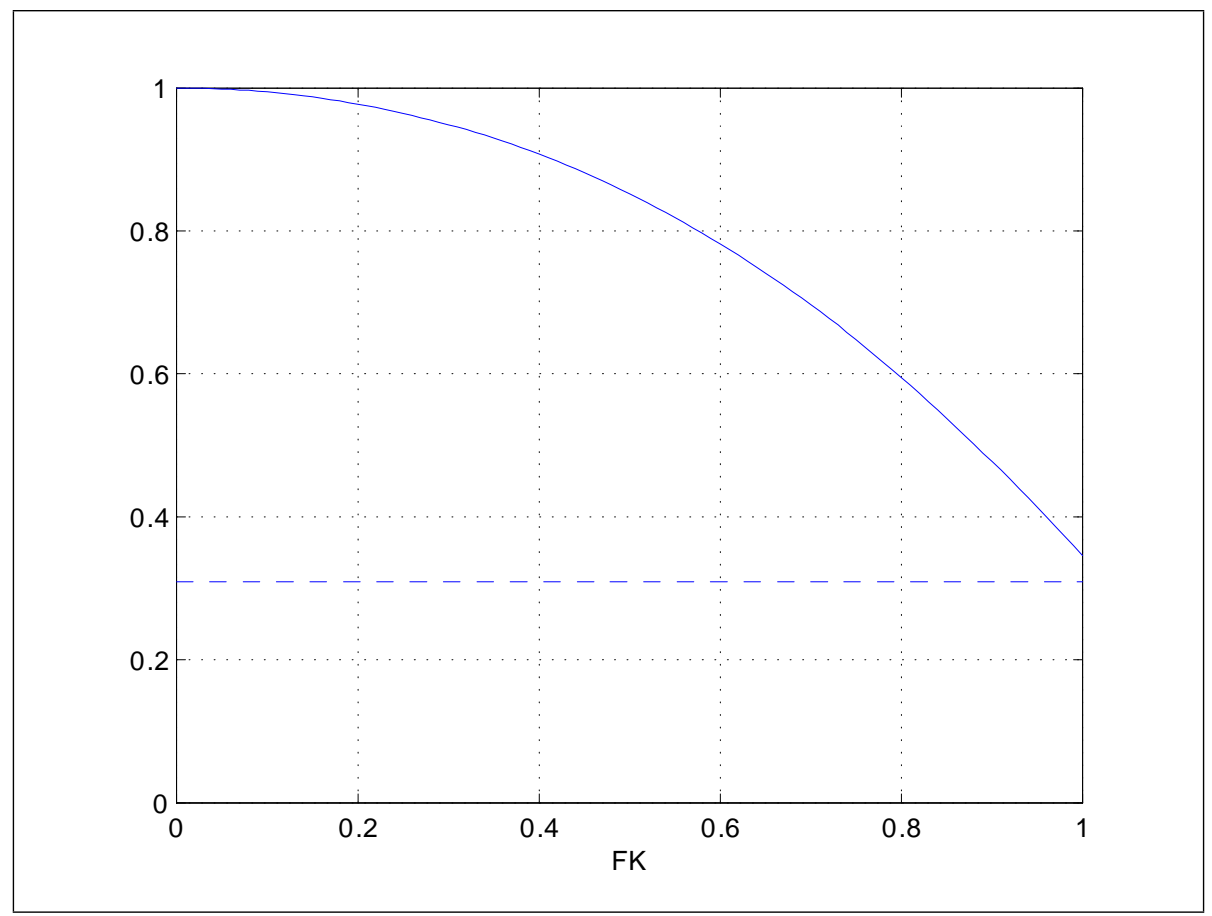

Figure 5: The expected cumulative effect on output, as a fraction of the response under uniform staggering, for different values of the FK index, following a shock to the interest rate rule. The FK index takes a value of zero under uniform staggering and a value of one under perfect synchronization. The dashed line corresponds to the case without real rigidities from either firm-specific capital or the Kimball aggregator.

an economy where prices are perfectly synchronized. In the latter case, the expected cumulative effect on output is only about 35 percent of the response under uniform staggering. This is almost as low as without real rigidities from either firm-specific capital or the Kimball aggregator, i.e., with a rental market for capital $(B=D=1)$ and the CES aggregator function $(A=1)$, corresponding to the dashed line in Figure $5 .^{10}$ In this case, $\frac{A D}{B}=1$ and the "synchronization term" in (33) drops out, so that output dynamics is unaffected by the degree of synchronization in price setting.

\footnotetext{
${ }^{10}$ With a rental market for capital, I still assume that the aggregate capital stock is fixed but that capital can be freely reallocated between firms. Output is produced by the constant returns to scale technology $Y_{i j t}=N_{i j t}^{\gamma} K_{i j t}^{1-\gamma}$, where $K_{i j t}$ is the firm's capital stock.
} 
But we are primarily interested in the empirically more realistic case when prices at the sector level are neither uniformly staggered nor perfectly synchronized. In other words, how the output persistence arising from the interaction between real rigidities and staggering is affected by prices being partially synchronized. As in the two-period model, the relationship between the degree of synchronization in price setting and the expected cumulative effect on output is non-linear. Starting from a situation with uniform staggering and introducing a small amount of synchronization, hence decreasing the reallocation of demand between firms in the same sector but increasing the reallocation of demand between different sectors has a smaller effect on the expected cumulative effect on output than performing the opposite experiment. When the FK index is $0.25,96$ percent of the uniformly staggered response remains; when the FK index is $0.5,85$ percent remains. For empirically plausible values of the FK index, uniform staggering provides a reasonably close approximation to aggregate dynamics under the true price setting structure. The basic results from the simple model in Section 3 carries over to this more realistic model.

\section{Conclusion}

Staggered price setting is crucial in creating persistent effects on output following a monetary policy shock. In the literature, it is routinely assumed that a constant fraction of firms reoptimize their prices each period, so there is no synchronization. In the present paper, I relax this assumption and allow for various degrees of synchronization in price setting. The main result is that deviations from uniform staggering have modest effects on persistence. Aggregate dynamics in the standard uniformly staggered pricing model is a reasonably accurate approximation of the dynamics in a more realistic model, where prices are neither uniformly staggered nor perfectly synchronized.

The intuitive reason for this is that non-adjusters have a disproportionately large influence on the behavior of the aggregate economy. When prices are strategic complements, the failure of a small group of price setters to reoptimize is sufficient to create persistent output effects. This result is coherent with those obtained in, e.g., 
Haltiwanger and Waldman (1989) and Fehr and Tyran (2008), who find that when agents vary in their ability to form expectations, rational agents tend to mimic the behavior of those less sophisticated so that the latter have a disproportionately large effect on the aggregate outcome. Similarly, Carvalho (2006) and Dixon and Kara (2007) find that, in economies with the same average duration of price or wage contracts, a monetary policy shock yields a larger and more persistent response, when a few contracts of longer durations are present. In the present model, a small step away from uniform staggering has a small effect on aggregate dynamics after a monetary policy shock, but a small step away from perfect synchronization leads to a considerable increase in persistence. 


\section{References}

Ball, L., Romer, D., 1990. Real rigidities and the non-neutrality of money. Review of Economic Studies 57, 183-203.

Calvo, G. A., 1983. Staggered prices in a utility-maximizing framework. Journal of Monetary Economics 12, 383-398.

Carrillo, J., Fève, P., Matheron, J., 2007. Monetary policy inertia or persistent shocks: A DSGE analysis. International Journal of Central Banking 3, 1-38.

Carvalho, C., 2006. Heterogeneity in price stickiness and the real effects of monetary shocks. Frontiers of Macroeconomics 2.

Chari, V. V., Kehoe, P. J., McGrattan, E. R., 2000. Sticky price models of the business cycle: Can the contract multiplier solve the persistence problem? Econometrica 68, 1151-1180.

Cornille, D., Dossche, M., 2006. The patterns and determinants of price setting in the Belgian industry. Research series 200605-1, National Bank of Belgium.

Cornille, D., Dossche, M., 2008. Some evidence on the adjustment of producer prices. Scandinavian Journal of Economics 110, 489-518.

Dhyne, E., Álvarez, L. J., Bihan, H. L., Veronese, G., Dias, D., Hoffmann, J., Jonker, N., Lünnemann, P., Rumler, F., Vilmunen, J., 2005. Price setting in the euro area: some stylized facts from individual consumer price data. Working Paper Series 524, European Central Bank.

Dhyne, E., Konieczny, J., 2007. Temporal distribution of price changes : Staggering in the large and synchronization in the small. Research series 200706-02, National Bank of Belgium.

Dixon, H., Kara, E., 2007. Persistence and nominal inertia in a generalized Taylor economy: How longer contracts dominate shorter contracts. Discussion Papers 07-01, Department of Economics, University of Birmingham. 
Eichenbaum, M., Fisher, J. D., 2007. Estimating the frequency of price reoptimization in Calvo-style models. Journal of Monetary Economics 54, 2032-2047.

Fehr, E., Tyran, J.-R., 2008. Limited rationality and strategic interaction: The impact of the strategic environment on nominal inertia. Econometrica 76, 353-394.

Fisher, T. C. G., Konieczny, J. D., 2000. Synchronization of price changes by multiproduct firms: evidence from Canadian newspaper prices. Economics Letters 68, $271-277$.

Haltiwanger, J. C., Waldman, M., 1989. Limited rationality and strategic complements: The implications for macroeconomics. The Quarterly Journal of Economics 104, 463-83.

Hausman, J., Leonard, G., Zona, J. D., 1994. Competitive analysis with differenciated products. Annales D'Économie et de Statistique, 159-180.

Kimball, M. S., 1995. The quantitative analytics of the basic neomonetarist model. Journal of Money, Credit and Banking 27, 1241-77.

Levin, A., Yun, T., 2008. Reconsidering the microeconomic foundations of pricesetting behavior, unpublished manuscript.

Romer, D., 2001. Advanced Macroeconomics. McGraw-Hill Education - Europe.

Taylor, J. B., 1980. Aggregate dynamics and staggered contracts. Journal of Political Economy 88, 1-23.

Veronese, G., Fabiani, S., Sabbatini, R., 2005. Consumer price behaviour in Italy evidence from micro cpi data. Working Paper Series 449, European Central Bank.

Woodford, M., 2005. Firm-specific capital and the New Keynesian Phillips curve. International Journal of Central Banking 1. 


\section{Appendices}

\section{A Solving for output dynamics in the two-period model}

Let $x_{t}$ denote the optimal price at $t$. Combining (2) with (5) and (6), one can write

$$
x_{t}=\phi m_{t}+\frac{(1-\phi)}{2}\left(p_{t}+E_{t} p_{t+1}\right) .
$$

Given the assumptions about price setting described in the text, the price level is

$$
p_{t}=(1-\alpha) x_{t}+\alpha x_{t-1}
$$

in odd periods, and

$$
p_{t}=\alpha x_{t}+(1-\alpha) x_{t-1}
$$

in even periods. Combining these with (A.1), yields

$$
x_{t}=\left(1-2 A_{I}\right) m_{t}+A_{I}\left(x_{t-1}+E_{t} x_{t+1}\right) .
$$

I guess that the equilibrium law of motion for $x_{t}$ is of the form

$$
x_{t}=\lambda_{I} x_{t-1}+\nu_{I} m_{t} .
$$

Repeated substitution of this into (A.4) gives that the optimal price must satisfy

$$
\left[\lambda_{1}-A_{1}\left(\lambda_{1} \lambda_{2}+1\right)\right] x_{t-1}+\left[\nu_{1}-A_{1}\left(\lambda_{2} \nu_{1}+\nu_{2}\right)-\left(1-2 A_{1}\right)\right] m_{t}=0
$$

in even periods, and

$$
\left[\lambda_{2}-A_{2}\left(\lambda_{1} \lambda_{2}+1\right)\right] x_{t-1}+\left[\nu_{2}-A_{2}\left(\lambda_{1} \nu_{2}+\nu_{1}\right)-\left(1-2 A_{2}\right)\right] m_{t}=0,
$$


in odd periods. It follows that the solution to $\left(\gamma_{1}, \gamma_{2}, \nu_{1}, \nu_{2}\right)$ is obtained by solving the system

$$
\begin{aligned}
\lambda_{1}-A_{1}\left(\lambda_{1} \lambda_{2}+1\right) & =0 \\
\lambda_{2}-A_{2}\left(\lambda_{1} \lambda_{2}+1\right) & =0 \\
\nu_{1}-A_{1}\left(\lambda_{2} \nu_{1}+\nu_{2}\right)-\left(1-2 A_{1}\right) & =0 \\
\nu_{2}-A_{2}\left(\lambda_{1} \nu_{2}+\nu_{1}\right)-\left(1-2 A_{2}\right) & =0 .
\end{aligned}
$$

It is easy to verify that $\nu_{I}=1-\lambda_{I}$, and that one can write (A.5) as

$$
x_{t}=\lambda_{I} x_{t-1}+\left(1-\lambda_{I}\right) m_{t}
$$

Substituting this into A.2 and (A.3), the price level can be written as

$$
p_{t}=\left[(1-\alpha) \lambda_{1}+\alpha\right] x_{t-1}+(1-\alpha)\left(1-\lambda_{1}\right) m_{t}
$$

in odd periods, and as

$$
p_{t}=\left[\alpha \lambda_{2}+(1-\alpha)\right] x_{t-1}+\alpha\left(1-\lambda_{2}\right) m_{t}
$$

in even periods. Substituting these into (5), aggregate demand can be written as

$$
y_{t}=-\left[(1-\alpha) \lambda_{1}+\alpha\right] x_{t-1}+\left[(1-\alpha) \lambda_{1}+\alpha\right] m_{t}
$$

in odd periods, and as

$$
y_{t}=-\left[\alpha \lambda_{2}+(1-\alpha)\right] x_{t-1}+\left[\alpha \lambda_{2}+(1-\alpha)\right] m_{t}
$$

in even periods.

Assuming that $t$ is odd, lagging (A.12) one period, taking into account that $t-1$ 
is even, and substituting this into (A.15), aggregate demand can be written as $y_{t}=-\left[(1-\alpha) \lambda_{1}+\alpha\right] \lambda_{2} x_{t-2}-\left[(1-\alpha) \lambda_{1}+\alpha\right]\left(1-\lambda_{2}\right) m_{t-1}+\left[(1-\alpha) \lambda_{1}+\alpha\right] m_{t}$,

or using that $m_{t}=m_{t-1}+\varepsilon_{t}$ as

$$
y_{t}=-\left[(1-\alpha) \lambda_{1}+\alpha\right] \lambda_{2} x_{t-2}+\left[(1-\alpha) \lambda_{1}+\alpha\right] \lambda_{2} m_{t-1}+\left[(1-\alpha) \lambda_{1}+\alpha\right] \varepsilon_{t} .
$$

It follows from (A.16) that aggregate demand at $t-1$ is given by

$$
y_{t-1}=-\left[\alpha \lambda_{2}+(1-\alpha)\right] x_{t-2}+\left[\alpha \lambda_{2}+(1-\alpha)\right] m_{t-1}
$$

Solving for $x_{t-2}$ and substituting this into (A.18), yields

$$
y_{t}=\frac{\left[(1-\alpha) \lambda_{1}+\alpha\right]}{\alpha \lambda_{2}+(1-\alpha)} \lambda_{2} y_{t-1}+\left[(1-\alpha) \lambda_{1}+\alpha\right] \varepsilon_{t} .
$$

Similar reasoning when $t$ is even, yields

$$
y_{t}=\frac{\left[\alpha \lambda_{2}+(1-\alpha)\right]}{(1-\alpha) \lambda_{1}+\alpha} \lambda_{1} y_{t-1}+\left[\alpha \lambda_{2}+(1-\alpha)\right] \varepsilon_{t} .
$$

The equilibrium law of motion for aggregate output can thus be written as (8) in the text, where the coefficients are given by the system in (9) - (12).

\section{B The expected cumulative effect on output in the two-period model}

The economy is initially in steady state and is hit by a shock of size $\varepsilon$ in $t$. Recalling that $y_{t}=\gamma_{I} y_{t-1}+\omega_{I} \varepsilon_{t}$, it then follows that

$$
y_{t}=\omega_{I} \varepsilon,
$$


and that

$$
E_{t} \varepsilon_{t+k}=0 \quad \forall k>0
$$

which can be used to calculate the following conditional expectations:

$$
\begin{aligned}
E_{t}\left(y_{t+2 k} \mid t \text { odd }\right) & =\gamma_{1} E_{t}\left(y_{t+2 k-1} \mid t \text { odd }\right) \\
& =\gamma_{1} \gamma_{2} E_{t}\left(y_{t+2 k-2} \mid t \text { odd }\right) \\
& =\ldots \\
& =\gamma_{1}\left(\gamma_{1} \gamma_{2}\right)^{k-1} E_{t}\left(y_{t+1} \mid t \text { odd }\right) \\
& =\left(\gamma_{1} \gamma_{2}\right)^{k} \omega_{1} \varepsilon \\
E_{t}\left(y_{t+2 k+1} \mid t \text { odd }\right) & =\gamma_{2} E_{t}\left(y_{t+2 k} \mid t \text { odd }\right) \\
& =\gamma_{2}\left(\gamma_{1} \gamma_{2}\right)^{k} \omega_{1} \varepsilon \\
E_{t}\left(y_{t+2 k} \mid t \text { even }\right) & =\gamma_{2} E_{t}\left(y_{t+2 k-1} \mid t \text { even }\right) \\
& =\gamma_{1} \gamma_{2} E_{t}\left(y_{t+2 k-2} \mid t \text { even }\right) \\
& =\ldots \\
& =\gamma_{2}\left(\gamma_{1} \gamma_{2}\right)^{k-1} E_{t}\left(y_{t+1} \mid t \text { even }\right) \\
& =\left(\gamma_{1} \gamma_{2}\right)^{k} \omega_{2} \varepsilon \\
& =\gamma_{1} E_{t}\left(y_{t+2 k} \mid t \text { even }\right) \\
E_{t}\left(y_{t+2 k+1} \mid t \text { even }\right) & \left.\gamma_{2}\right)^{k} \omega_{2} \varepsilon .
\end{aligned}
$$

Putting these together, the unconditional expectations are given by

$$
E_{t} y_{t+2 k}=\frac{\varepsilon}{2}\left(\omega_{1}+\omega_{2}\right)\left(\gamma_{1} \gamma_{2}\right)^{k}
$$

and

$$
E_{t} y_{t+2 k+1}=\frac{\varepsilon}{2}\left(\gamma_{2} \omega_{1}+\gamma_{1} \omega_{2}\right)\left(\gamma_{1} \gamma_{2}\right)^{k}
$$


It follows that

$$
E_{t} y_{t+2 k}+E_{t} y_{t+2 k+1}=\frac{\varepsilon}{2}\left[\omega_{1}\left(1+\gamma_{2}\right)+\omega_{2}\left(1+\gamma_{1}\right)\right]\left(\gamma_{1} \gamma_{2}\right)^{k}
$$

and that one can write

$$
\begin{aligned}
E_{t} \sum_{k=0}^{\infty} y_{t+k} & =E_{t} \sum_{k=0}^{\infty}\left[y_{t+2 k}+y_{t+2 k+1}\right] \\
& =\frac{\varepsilon}{2}\left[\omega_{1}\left(1+\gamma_{2}\right)+\omega_{2}\left(1+\gamma_{1}\right)\right] \sum_{k=0}^{\infty}\left(\gamma_{1} \gamma_{2}\right)^{k} \\
& =\frac{\varepsilon}{2} \frac{\left[\omega_{1}\left(1+\gamma_{2}\right)+\omega_{2}\left(1+\gamma_{1}\right)\right]}{1-\gamma_{1} \gamma_{2}}
\end{aligned}
$$

\section{Proof of Proposition 5}

The expected cumulative effect on output can, using (9) - (12), be rewritten as

$$
\begin{aligned}
C(a, \phi) & =\frac{\varepsilon}{2} \frac{\left[\omega_{1}\left(1+\gamma_{2}\right)+\omega_{2}\left(1+\gamma_{1}\right)\right]}{1-\gamma_{1} \gamma_{2}} \\
& =\frac{\varepsilon}{2}\left[\frac{\omega_{1}\left(1+\frac{\omega_{2}}{\omega_{1}} \lambda_{1}\right)+\omega_{2}\left(1+\frac{\omega_{1}}{\omega_{2}} \lambda_{2}\right)}{1-\left(\frac{\omega_{1}}{\omega_{2}} \lambda_{2}\right)\left(\frac{\omega_{2}}{\omega_{1}} \lambda_{1}\right)}\right] \\
& =\frac{\varepsilon}{2}\left[\frac{\omega_{1}+\omega_{2} \lambda_{1}+\omega_{2}+\omega_{1} \lambda_{2}}{1-\lambda_{1} \lambda_{2}}\right] \\
& =\frac{\varepsilon}{2}\left[\frac{1+2(1-\alpha) \lambda_{1}+2 \alpha \lambda_{2}+\lambda_{1} \lambda_{2}}{1-\lambda_{1} \lambda_{2}}\right] \\
& =\frac{\varepsilon}{2}\left[\frac{2\left[1+(1-\alpha) \lambda_{1}+\alpha \lambda_{2}\right]}{1-\lambda_{1} \lambda_{2}}-1\right]
\end{aligned}
$$


Next, using (18) and (19) one can write

$$
\begin{aligned}
(1-\alpha) \lambda_{1}+\alpha \lambda_{2} & =(1-\alpha) \frac{1-\sqrt{1-4 A_{1} A_{2}}}{2 A_{2}}+\alpha \frac{1-\sqrt{1-4 A_{1} A_{2}}}{2 A_{1}} \\
& =\left[1-\sqrt{1-4 A_{1} A_{2}}\right]\left[\frac{(1-\alpha)}{2 A_{2}}+\frac{\alpha}{2 A_{1}}\right] \\
& =\left[1-\sqrt{1-4 A_{1} A_{2}}\right] \frac{\left[(1-\alpha) A_{1}+\alpha A_{2}\right]}{2 A_{1} A_{2}} \\
& =\left[1-\sqrt{1-4 A_{1} A_{2}}\right] \frac{(1+\phi)}{(1-\phi)}
\end{aligned}
$$

The last line follows by using the definitions of $A_{1}$ and $A_{2}$, so that the nominator in the second term at the third line can be written as

$$
\begin{aligned}
(1-\alpha) A_{1}+\alpha A_{2} & =\frac{\alpha(1-\alpha)(1-\phi)}{2(\phi+\alpha(1-\phi))}+\frac{\alpha(1-\alpha)(1-\phi)}{2(\phi+(1-\alpha)(1-\phi))} \\
& =\frac{\left.2 \alpha(1-\alpha)(1-\phi)[(\phi+(1-\alpha)(1-\phi))+(\phi+\alpha(1-\phi))]_{3}\right)}{4(\phi+\alpha(1-\phi))(\phi+(1-\alpha)(1-\phi))}
\end{aligned}
$$

and the denominator as

$$
2 A_{1} A_{2}=\frac{2 \alpha(1-\alpha)(1-\phi)^{2}}{4(\phi+\alpha(1-\phi))(\phi+(1-\alpha)(1-\phi))},
$$

so that

$$
\begin{aligned}
\frac{\left[(1-\alpha) A_{1}+\alpha A_{2}\right]}{2 A_{1} A_{2}} & =\frac{2 \alpha(1-\alpha)(1-\phi)[(\phi+(1-\alpha)(1-\phi))+(\phi+\alpha(1-\phi))]}{2 \alpha(1-\alpha)(1-\phi)^{2}} \\
& =\frac{1}{(1-\phi)}[(\phi+(1-\alpha)(1-\phi))+(\phi+\alpha(1-\phi))] \\
& =\frac{(1+\phi)}{(1-\phi)} .
\end{aligned}
$$


One can also write

$$
\begin{aligned}
1-\lambda_{1} \lambda_{2} & =1-\frac{\left[1-\sqrt{1-4 A_{1} A_{2}}\right]^{2}}{4 A_{1} A_{2}} \\
& =\frac{4 A_{1} A_{2}-1+2 \sqrt{1-4 A_{1} A_{2}}-\left[1-4 A_{1} A_{2}\right]}{4 A_{1} A_{2}} \\
& =\frac{-2\left[1-A_{1} A_{2}\right]+2 \sqrt{1-4 A_{1} A_{2}}}{4 A_{1} A_{2}} \\
& =\frac{2}{4 A_{1} A_{2}} \sqrt{1-4 A_{1} A_{2}}\left[1-\sqrt{1-4 A_{1} A_{2}}\right] .
\end{aligned}
$$

Substituting (C.2) and (C.6) back into (C.1) yields

$$
\begin{aligned}
C(a, \phi) & =\frac{\varepsilon}{2}\left[\frac{4 A_{1} A_{2}\left[1+\left[1-\sqrt{1-4 A_{1} A_{2}}\right] \frac{(1+\phi)}{(1-\phi)}\right]}{\sqrt{1-4 A_{1} A_{2}}\left[1-\sqrt{1-4 A_{1} A_{2}}\right]}-1\right] \\
& =\frac{\varepsilon}{2}\left[\frac{1}{1-\phi} \frac{4 A_{1} A_{2}\left[2-(1+\phi) \sqrt{1-4 A_{1} A_{2}}\right]}{\sqrt{1-4 A_{1} A_{2}}\left[1-\sqrt{1-4 A_{1} A_{2}}\right]}-1\right] \\
& =\frac{\varepsilon}{2}\left[\frac{1}{1-\phi} \frac{1+\sqrt{1-4 A_{1} A_{2}}}{\sqrt{1-4 A_{1} A_{2}}}\left[2-(1+\phi) \sqrt{1-4 A_{1} A_{2}}\right]-1\right] .
\end{aligned}
$$

\section{Proof of Proposition 6}

I first show that $\arg \max _{\alpha} \Omega(\alpha, \phi)=\frac{1}{2}$. Define

$$
\begin{aligned}
F(\alpha, \phi) & \equiv \alpha(1-\alpha)(1-\phi)^{2} \\
G(\alpha, \phi) & \equiv 4 A_{1} A_{2}=\frac{F}{[\phi+F]} \\
S(\alpha, \phi) & \equiv \sqrt{1-4 A_{1} A_{2}} .
\end{aligned}
$$


The first derivatives with respect to $\alpha$ are given by

$$
\begin{aligned}
F_{1}(\alpha, \phi) & =(1-2 \alpha)(1-\phi)^{2} \\
G_{1}(\alpha, \phi) & =\frac{\phi}{[\phi+F]^{2}} F_{1}, \\
S_{1}(\alpha, \phi) & =-\frac{1}{2}(1-G)^{-1 / 2} G_{1} .
\end{aligned}
$$

First, write $\Omega(\alpha, \phi)$ as

$$
\frac{2}{S}-(1+\phi)+2-(1+\phi) S
$$

Differentiating this with respect to $\alpha$ and setting the resulting derivative to zero yields

$$
-S_{1}\left[2[S]^{-2}+(1+\phi)\right]=0
$$

From the definition of $S$, the term inside the bracket is positive, and one can write

$$
S_{1}=0
$$

or

$$
\frac{1}{2}[1-G]^{-1 / 2} G_{1}=0
$$

From the definition of $G$, the term inside the bracket is positive, and one can write

$$
G_{1}=0
$$

or

$$
\left[\frac{\phi}{[\phi+F]^{2}}\right] F_{1}=0
$$

From the definition of $F$, the term inside the bracket is positive, and one can write

$$
F_{1}=0
$$

or

$$
(1-2 \alpha)(1-\phi)^{2}=0
$$


which yields $\alpha=\frac{1}{2}$.

Next, I show that $\Omega(\alpha, \phi)$ is a strictly concave function (has a negative second derivative) of $\alpha$. Let $F(\alpha, \phi), G(\alpha, \phi)$, and $S(\alpha, \phi)$ be defined as above, with the second derivatives with respect to $\alpha$ given by

$$
\begin{aligned}
F_{11}(\alpha, \phi) & =-2(1-\phi)^{2}, \\
G_{11}(\alpha, \phi) & =\frac{\phi}{[\phi+F]^{2}}\left[F_{11}-\frac{2\left[F_{1}\right]^{2}}{[\phi+F]}\right] \\
S_{11}(\alpha, \phi) & =-\frac{1}{4}(1-G)^{-3 / 2}\left[G_{1}\right]^{2}-\frac{1}{2}(1-G)^{-1 / 2} G_{11} .
\end{aligned}
$$

Differentiating $\Omega(\alpha, \phi)$ twice with respect to $\alpha$ yields

$$
4[S]^{-3}\left[S_{1}\right]^{2}-2[S]^{-2} S_{11}-(1+\phi) S_{11} .
$$

For $\Omega(\alpha, \phi)$ to be strictly concave requires that this expression is negative; a sufficient condition is that:

$$
\begin{aligned}
2[S]^{-2} S_{11} & >4[S]^{-3}\left[S_{1}\right]^{2} \\
S_{11} & >0 .
\end{aligned}
$$

Using the definition of $G$, these can be written as

$$
\begin{aligned}
G_{11} & <-\frac{3}{2}(1-G)^{-1}\left[G_{1}\right]^{2}, \\
G_{11} & <-\frac{1}{2}(1-G)^{-1}\left[G_{1}\right]^{2} .
\end{aligned}
$$

The condition in (D.10) is stronger, so it is sufficient to prove this inequality, which, using the definition of $F$, can be written as

$$
\frac{\phi}{[\phi+F]^{2}}\left[F_{11}-\frac{2\left[F_{1}\right]^{2}}{[\phi+F]}\right]<-\frac{3}{2} \frac{[\phi+F]}{\phi} \frac{\phi^{2}\left[F_{1}\right]^{2}}{[\phi+F]^{4}},
$$

or rearranging as 


$$
F_{11}<\frac{1}{2} \frac{\left[F_{1}\right]^{2}}{\phi+F}
$$

It follows from the definition of $F$ that the inequality in (D.13) is always satisfied.

\section{E Results for alternative permutation sequences}

There are 6 unique permutation sequences, listed in the table below. The monotoni-

\begin{tabular}{|c|c|c|c|}
\hline Sequence & $F K=0.25$ & $F K=0.5$ & $F K=0.75$ \\
\hline$(1,2,3,4)$ & 0.9646 & 0.8519 & 0.6478 \\
\hline$(1,2,4,3)$ & 0.9615 & 0.8442 & 0.6421 \\
\hline$(1,3,2,4)$ & 0.9765 & 0.8951 & 0.7185 \\
\hline$(1,3,4,2)$ & 0.9617 & 0.8481 & 0.6607 \\
\hline$(1,4,2,3)$ & 0.9771 & 0.8983 & 0.7232 \\
\hline$(1,4,3,2)$ & 0.9658 & 0.8607 & 0.6725 \\
\hline
\end{tabular}

Table E.1: The expected cumulative effect on output, as a fraction of that under uniform staggering, for different permutation sequences and various values of the FK index.

cally declining sequence used in the main text corresponds to the sequence $(1,2,3,4)$. Also listed in the table is the expected cumulative effect on output, as a fraction of the uniformly staggered response, for $F K=0.25,0.5,0.75$ for each sequence. 


\section{WORKING PAPERS*}

Editor: Nils Gottfries

2008:5 Ranjula Bali Swain and Adel Varghese, Does Self Help Group Participation Lead to Asset Creation. 25pp.

2008:6 Niklas Bengtsson, Do Protestant Aid Organizations Aid Protestants Only? 28pp.

2008:7 Mikael Elinder, Henrik Jordahl and Panu Poutvaara, Selfish and Prospective Theory and Evidence of Pocketbook Voting. 31pp.

2008:8 Erik Glans, The effect of changes in the replacement rate on partial retirement in Sweden. 30pp.

2008:9 Erik Glans, Retirement patterns during the Swedish pension reform. 44pp.

2008:10 Stefan Eriksson and Jonas Lageström, The Labor Market Consequences of Gender Differences in Job Search. 16pp.

2008:11 Ranjula Bali Swain and Fan Yang Wallentin, Economic or Non-Economic Factors - What Empowers Women?. 34pp.

2008:12 Matz Dahlberg, Heléne Lundqvist and Eva Mörk, Intergovernmental Grants and Bureaucratic Power. 34pp.

2008:13 Matz Dahlberg, Kajsa Johansson and Eva Mörk, On mandatory activation of welfare receivers. $39 \mathrm{pp}$.

2008:14 Magnus Gustavsson, A Longitudinal Analysis of Within-Education-Group Earnings Inequality. 26pp.

2008:15 Henrique S. Basso, Delegation, Time Inconsistency and Sustainable Equilibrium. 24pp.

2008:16 Sören Blomquist and Håkan Selin, Hourly Wage Rate and Taxable Labor Income Responsiveness to Changes in Marginal Tax Rates. 31 pp.

2008:17 Jie Chen and Aiyong Zhu, The relationship between housing investment and economic growth in China : A panel analysis using quarterly provincial data. 26pp.

2009:1 Per Engström, Patrik Hesselius and Bertil Holmlund, Vacancy Referrals, Job Search, and the Duration of Unemployment: A Randomized Experiment. $25 \mathrm{pp}$.

2009:2 Chuan-Zhong Li and Gunnar Isacsson, Valuing urban accessibility and air quality in Sweden: A regional welfare analysis. 24pp.

\footnotetext{
* A list of papers in this series from earlier years will be sent on request by the department.
} 
2009:3 Luca Micheletto, Optimal nonlinear redistributive taxation and public good provision in an economy with Veblen effects. $26 \mathrm{pp}$.

2009:4 Håkan Selin, The Rise in Female Employment and the Role of Tax Incentives. An Empirical Analysis of the Swedish Individual Tax Reform of $1971.38 \mathrm{pp}$.

2009:5 Lars M. Johansson and Jan Pettersson, Tied Aid, Trade-Facilitating Aid or Trade-Diverting Aid? 47pp.

2009:6 Håkan Selin, Marginal tax rates and tax-favoured pension savings of the selfemployed Evidence from Sweden. 32pp.

2009:7 Tobias Lindhe and Jan Södersten, Dividend taxation, share repurchases and the equity trap. $27 \mathrm{pp}$.

2009:8 Che-Yuan Liang, Nonparametric Structural Estimation of Labor Supply in the Presence of Censoring. 48pp.

2009:9 Bertil Holmlund, Incentives in Business and Academia. 12pp.

2009:10 Jakob Winstrand, The Effects of a Refinery on Property Values - The Case of Sweden. 27pp.

2009:11 Ranjula Bali Swain and Adel Varghese. The Impact of Skill Development and Human Capital Training on Self Help Groups. 28pp.

2009:12 Mikael Elinder. Correcting Mistakes: Cognitive Dissonance and Political Attitudes in Sweden and the United States. 25 pp.

2009:13 Sören Blomquist, Vidar Christiansen and Luca Micheletto: Public Provision of Private Goods and Nondistortionary Marginal Tax Rates: Some further Results. 41pp.

2009:14 Mattias Nordin: The effect of information on voting behavior. 34pp.

2009:15 Anders Klevmarken, Olle Grünewald and Henrik Allansson A new consumer price index that incorporates housing. $27 \mathrm{pp}$.

2009:16 Heléne L. Nilsson How Local are Local Governments? Heterogeneous Effects of Intergovernmental Grants. 41pp.

2009:17 Olof Åslund, Per-Anders Edin, Peter Fredriksson and Hans Grönqvist: Peers, neighborhoods and immigrant student achievement - evidence from a placement policy. $27 \mathrm{pp}$.

2009:18 Yunus Aksoy, Henrique S. Basso and Javier Coto-Martinez: Lending Relationships and Monetary Policy. 42 pp.

See also working papers published by the Office of Labour Market Policy Evaluation http://www.ifau.se/ 